\title{
Serum Soluble Interleukin 2 Receptor Alpha vs Urinary Parameters as a monitoring tool of treatment response of Lupus Nephritis and their relation to Lupus Nephritis Class on renal biopsy
}

\author{
Saiful Bahar Khan ${ }^{* 1}$, Syed Imtiaz Ahmed ${ }^{2}$, Md. Zayeed Ahsan ${ }^{3}$, Richmond Ronald Gomes ${ }^{4}$, Moin Shahid ${ }^{5}$ \\ ${ }^{1}$ Assistant Professor, Nephrology, Ad-din Women's Medical College, Dhaka, Bangladesh \\ ${ }^{2}$ Assistant registrar, Nephrology, National Institute of Kidney Diseases \& Urology (NIKDU) \\ ${ }^{3}$ Medical officer (OSD) Directorate General of Health Services. \\ ${ }^{4}$ Associate Professor, Medicine, Ad-din Women's Medical College, Dhaka, Bangladesh \\ ${ }^{5}$ Associate Professor, Endocrinology, Ad-din Women's Medical College, Dhaka, Bangladesh
}

Address for correspondence:

Dr. Saiful Bahar Khan, Assistant Professor, Nephrology, Ad-din Women’s Medical College Hospital, Dhaka, Bangladesh. E- mail: drsbkhan.edu@gmail.com

Submitted: 10 August 2020

Approved: 18 August 2020

Published: 19 August 2020

How to cite this article: Khan S. B., Ahmed S. I., Ahsan M. Z., Gomes R.R, Shahid M. Serum Soluble Interleukin 2 Receptor Alpha vs Urinary Parameters as a monitoring tool of treatment response of Lupus Nephritis and their relation to Lupus Nephritis Class on renal biopsy. G Med Sci. 2020; 1(4): 036-043. https://www.doi.org/10.46766/thegms.nephro.20081006

Copyright: @ 2020 Saiful Bahar Khan, Syed Imtiaz Ahmed, Md. Zayeed Ahsan, Richmond Ronald Gomes, Moin Shahid. This is an open access article distributed under the Creative Commons Attribution License, which permits unrestricted use, distribution, and reproduction in any medium, provided the original work is properly cited.

\section{ABSTRACT}

Background: Lupus Nephritis (LN) is one of the most common and serious manifestations in SLE patients that causes significant morbidity and mortality. Current conventional biomarkers for lupus nephritis like urine sediments, proteinuria, anti-dsDNA antibodies and C3 or C4 are sometimes mislead for prediction of treatment response. Recently IL-2 R alpha has shown to be a good marker to predict treatment response of lupus nephritis. Objective: The main objective of this study was to compare serum sIL-2R alpha with urinary parameters including 24 hours urinary total protein (UTP) as a marker of treatment response of lupus nephritis (LN) and their relation to the LN class on renal biopsy. Methods: This prospective observational study was conducted in the Department of Nephrology and Department of Rheumatology, Bangabandhu Sheikh Mujib Medical University (BSMMU), Dhaka From July 2018 to August 2019. Twenty-seven patients who were diagnosed with lupus nephritis after kidney biopsy were included in this study. Serum soluble interleukin-2 receptor alpha, Urine routine examination and 24 hrs UTP were measured in all patient at baseline, 3-month and 6- month after treatment. Serum soluble interleukin-2 receptor alpha level was measured by ELISA and is expressed as pg/ mg. Serum sIL-2R alpha as well as urinary parameter results were compared before and after treatment and in between treatment response and nonresponse group. Results: Serum sIL-2R alpha levels were significantly higher in patients of proliferative lupus nephritis (Class III \& Class IV) than non-proliferative lupus nephritis (Class V) at base line (3934.3 $\pm 1095.2,3934.3 \pm 1095.2 \& 1801.98 \pm 205.8 \mathrm{pg} / \mathrm{ml} \mathrm{respectively)} \mathrm{and} \mathrm{levels}$ were decreased significantly 6 month after treatment $(\mathrm{p}<0.001)$. Serum sIL-2R alpha levels were also significantly higher in non-remission proliferative group then remission proliferative group ( $4071.60 \pm 769.91 \mathrm{Vs} 5169.20 \pm 394.76 \mathrm{pg} / \mathrm{ml}$ ) with p value 0.008 at base line. In contrast no significant difference were observed for 24 hrs UTP levels at base line between these groups which suggest that serum sIL-2R alpha is more sensitive marker than 24 hrs UTP in predicting treatment response of lupus nephritis. Conclusions: Serum sIL-2R alpha might be a valuable serological biomarker to diagnose and to predict and monitor the treatment response of lupus nephritis 


\section{Introduction}

Systemic Lupus Erythematosus (SLE) is a chronic autoimmune disease which affects almost every system in the body with different degrees of severity [1]. One of the most common manifestations of SLE is lupus nephritis [2]. At presentation up to $50 \%$ of SLE patients will have clinically evident kidney disease and $60 \%$ during follow-up [3]. Though renal biopsy is the gold standard for providing information on the histological classes of lupus nephritis and assessing response to therapy but frequently repeating biopsies is an unrealistic management tool to monitor response [4]. Treatment response in lupus nephritis (LN) is defined clinically, without consideration of renal histology [5]. However, these traditional markers are often not as specific as desired in situations of diagnostic dilemma [6]. In addition, persistent proteinuria does not always reflect ongoing disease activity and could also be due to renal damage. Repeat kidney biopsy, though useful, is an invasive procedure with its own complications [7]. Furthermore, none of these traditional markers has been shown to possess the ability to predict histology [2]. Thus, future research should be undertaken to evaluate novel biomarkers that can facilitate early diagnosis, assessing disease severity and predict and monitor treatment response, disease progress and predict renal flare are clearly necessary [8][9].

One of these biomarkers is soluble Interleukin-2 receptor alpha. Previous studies have reported that IL-2R levels were higher in patients with SLE than that in controls [10]. Higher levels of $1 \mathrm{~L}-2 \mathrm{R}$ in the serum was found to be related to severe lupus nephritis, serum IL-2R levels were found to be correlated positively with anti-dsDNA titers and negatively with serum C3 and C4 levels in such patients [10]. Serum sIL-2R correlated to the activity of the disease as well [11]. Follow up of the lupus nephritis patients after treatment showed decreased serum $1 \mathrm{~L}-2 \mathrm{R}$ levels with reduction of disease activity [10]. Serum soluble IL-2a receptor is more sensitive markers of disease activity than C3 or C4 in predicting improvement [10].

Thus, this marker may have the potential to serve as novel marker for detection of lupus nephritis and assessment of its activity and treatment response. In this study serum SIL-2R alpha has been evaluated as a marker for diagnosis and prediction of treatment response of lupus nephritis.

\section{Materials and Method}

This prospective observational study was conducted in the Department of Nephrology and Department of Rheumatology, Bangabandhu Sheikh Mujib Medical University (BSMMU), Dhaka, Bangladesh from July 2018 to August 2019 among twenty-seven patients (27) who were diagnosed with lupus nephritis after kidney biopsy. All participants were explained about the natural history, pathophysiology, relevant investigations, current treatment options and outcome of lupus nephritis prior to enrollment. Renal biopsy was done after taking informed written consent who willingly agreed to participate in this study.

\section{Inclusion criteria}

1. Age $\geq 18$ years of both sexes

2. Diagnosed case of SLE with lupus nephritis, according to revised ACR criteria.

3. Biopsy proven class III, IV \& V lupus nephritis.

\section{Exclusion criteria}

1. Pregnant and lactating women.

2. Patients with malignancy.

3. Patients with active infection.

4. Patients with autoimmune disease other than SLE.

5. End stage renal disease or dialysis dependent patients.

The renal histology was classified according to the International Society of Nephrology/Renal Pathology Society. According to the abbreviated version of the classification, combined classes III/V or IV/V will be considered as class III or IV, respectively. Out of those patients who were class III, IV and V; LN diagnosed histologically without any features of exclusion criteria and willing to participate in this study, so they were finally enrolled for this study. Renal SLEDAI (rSLEDAI) was used to assess kidney disease activity. The score consists of the four kidney-related parameters: hematuria, pyuria, proteinuria, and urinary casts. Scores for the renal SLEDAI ranged from 0 (inactive renal disease) to a maximum of 16 . Active lupus nephritis was those with an rSLEDAI score of 4 or more. Then they were thoroughly 
appraised about the study as well as drug treatment and follow up. Before starting the treatment base line levels of CBC, ESR, CRP, Urine R/M/E, UTP, S. Creatinine, S. Electrolytes, S. ALT, ANA, Anti-dsDNA, C3, C4, Serum levels of soluble interleukin-2 receptor alpha were measured and after starting the treatment levels of CBC, ESR, Urine R/M/E, UTP, S. Creatinine, Anti-dsDNA, C3, C4, and serum levels of soluble interleukin-2 receptor alpha were measured at 3rd and 6th month. Patients were receiving either intravenous Cyclophosphamide $(0.5-1 \mathrm{~g} / \mathrm{m} \mathrm{2}$ ) monthly for 6 months (NIH protocol) or MMF (2 gm/day) as induction therapy for 6 months along with corticosteroid $1 \mathrm{mg} / \mathrm{kg}$ body weight and after 6 months all patient received Tab. MMF $1 \mathrm{gm}$ and Tab. Prednisolone 5 to $7.5 \mathrm{mg}$ daily. All patients of LN of any class should be treated with hydroxychloroquine, unless they have a specific contraindication to this drug (KDIGO, 2012).

$3 \mathrm{ml}$ of venous blood was collected from study subject and then centrifuged to separate serum at $1000 \mathrm{rmp}$ for 15 minutes. These samples are then stored in $-80^{\circ} \mathrm{C}$ in the microbiology lab of BSMMU. Serum levels of soluble interleukin-2 receptor alpha were measured by using the colorimetric ELISA kit (YLbiont, Shanghai, Chaina) according to the manufacturer's instructions.

Computer based statistical analysis was carried out with appropriate techniques and systems. All data were recorded systematically in proforma data collection form. Quantitative data were expressed as mean and standard deviation and qualitative data were expressed as frequency distribution and percentage. Statistical analyses were performed by using windows-based computer software with Statistical Packages for Social Sciences (SPSS-23) (Armonk, NY: IBM Corp). Level of significance were seen by pair t-tests, unpair t-test and Youden index for best cut-off value. Correlation between variable was examined by Pearson's correlation test. For all statistical tests, we considered p value $<0.05$ as statistically significant.

\section{Results}

In this prospective observational study, a total of 27 patients with lupus nephritis were recruited. Most of the study subjects were females 24 (88.9\%). Maximum were in the age group of $21-30$ (44.4\%) years. Renal biopsy was done in all patients. Among 27 lupus nephritis patients, the most common histopathological type was class IV (48.1\%) followed by class V (33.3\%) and class III (18.5\%).

\begin{tabular}{|l|l|l|}
\hline & \multicolumn{1}{|c|}{ Frequency (n) } & Percentage (\%) \\
\hline Age & \multicolumn{1}{|c|}{} \\
\hline$\leq 20$ & 8 & 29.6 \\
\hline $21-30$ & 12 & 44.4 \\
\hline$>30$ & 7 & 25.9 \\
\hline Gender & & \\
\hline Male & 3 & 11.1 \\
\hline Female & 24 & 88.9 \\
\hline ISN/RPS classification & & \\
\hline Class III & 5 & 18.5 \\
\hline Class IV & 13 & 48.1 \\
\hline Class V & 9 & 33.3 \\
\hline
\end{tabular}

Table I: Baseline characteristics of the study subjects 
Urine RME findings of 27 lupus nephritis patients at baseline and after 3 months and after 6 months of treatment are show in Table 2.

\begin{tabular}{|l|c|c|c|}
\hline & Baseline & After 3 months & After 6 months \\
\hline Pus cell (cells per HPF) & $13.74 \pm 15.38$ & $5.62 \pm 5.73$ & $3.37 \pm 1.33$ \\
\hline RBC (cells per HPF) & $41.07 \pm 51.49$ & $4.29 \pm 7.22$ & $2.11 \pm 3.60$ \\
\hline Protein & & & \\
\hline Nil & $0(0.0)$ & $2(7.4)$ & $7(25.9)$ \\
\hline+ & $0(0.0)$ & $7(25.9)$ & $6(22.2)$ \\
\hline++ & $10(37.0)$ & $12(44.4)$ & $6(22.2)$ \\
\hline+++ & $16(59.3)$ & $6(22.2)$ & $3(11.1)$ \\
\hline++++ & $1(3.7)$ & $0(0.0)$ & $0(0.0)$ \\
\hline CAST & $6(22.2)$ & & \\
\hline
\end{tabular}

SD: Standard deviation, RME: Routine microscopic examination, HPF: High power field.

Table 2: Urine RME of the study subjects at baseline, after 3 month and 6 month of treatment $(n=27)$

At baseline Serum sIL-2Ra level is significantly higher $(\mathrm{p}=<0.001)$ in proliferative (class III+IV) then membranous (class V) lupus nephritis but 24 hrs UTP is significantly higher $(\mathrm{p}=<0.001)$ in membranous (class V) then proliferative (class III+IV).

\begin{tabular}{|l|c|c|c|}
\hline \multicolumn{1}{|c|}{ Parameters } & Proliferative (class III+IV) & Non proliferative (class V) & p-value \\
\hline sIL-2Ra (pg/ml) & $4376.49 \pm 843.20$ & $1801.98 \pm 205.82$ & $<0.001$ \\
\hline UTP $(\mathrm{gm} /$ day) & $2.84 \pm 1.00$ & $5.07 \pm 2.06$ & 0.001 \\
\hline Renal SLEDAI & $12.22 \pm 3.21$ & $5.33 \pm 2.83$ & $<0.001$ \\
\hline SLEDAI & $21.33 \pm 4.34$ & $10.44 \pm 5.64$ & $<0.001$ \\
\hline
\end{tabular}

Unpaired ' $t$ ' test was done to examine the level of significance

\section{Table 3: sIL-2Ra, UTP and disease activity index of the study subjects at baseline $(n=27)$}

Pre-treatment (at baseline) and post treatment (after 6 month) value of sIL-2Ra in proliferative LN (class Class III \& Class IV) was $4376.49 \pm 843.20(\mathrm{pg} / \mathrm{ml})$ and $1563.26 \pm 1126.89(\mathrm{pg} / \mathrm{ml})$ respectively and in membranous (Class V) lupus nephritis was $1801.98 \pm 205.82(\mathrm{pg} / \mathrm{ml})$ and $753.62 \pm 299.47(\mathrm{pg} / \mathrm{ml})$ respectively. Pre-treatment (at baseline) and post treatment (after 6 month) value of UTP in proliferative LN (class Class III \& Class IV) was $2.84 \pm 1.00$ (gm/ day) \& $1.53 \pm 1.50$ (gm/day) respectively and in membranous (Class V) lupus nephritis was $5.07 \pm 2.06 \& 1.37 \pm 1.12$ (gm/day) respectively. The value of serum sIL-2Ra, $24 \mathrm{hr}$ UTP were significantly different before and after treatment with $\mathrm{p}$ value $<0.05$. 


\begin{tabular}{|l|c|c|}
\hline & $\begin{array}{c}\text { Proliferative (Class III+IV) } \\
\mathbf{n = 1 8}\end{array}$ & $\begin{array}{c}\text { Non Proliferative(Class V) } \\
\mathbf{n = 9}\end{array}$ \\
\hline sIL-2Ra (pg/ml) & \multicolumn{2}{|c|}{} \\
\hline Baseline & $4376.49 \pm 843.20$ & $1801.98 \pm 205.82$ \\
\hline After 6 months & $1563.26 \pm 1126.89$ & $753.62 \pm 299.47$ \\
\hline \% change & $65.99 \pm 20.28$ & $57.66 \pm 16.64$ \\
\hline p-value & $<0.001$ & $<0.001$ \\
\hline 24 hrs UTP (gm/day) & $2.84 \pm 1.00$ & $5.07 \pm 2.06$ \\
\hline Baseline & $1.53 \pm 1.50$ & $1.37 \pm 1.12$ \\
\hline After 6 months & $46.12 \pm 47.94$ & $72.89 \pm 24.76$ \\
\hline \% change & 0.003 & $<0.001$ \\
\hline p-value &
\end{tabular}

Table 4: IL-2R and UTP level at baseline and after 6 months proliferative and non-proliferative patients $(\mathrm{n}=27)$.

Pre-treatment (at baseline) and post treatment (after 6 month) value of sIL-2Ra in remission group of proliferative lupus nephritis (class III and class IV) was $4071.60 \pm 769.91(\mathrm{pg} / \mathrm{ml})$ and $925.98 \pm 363.10(\mathrm{pg} / \mathrm{ml})$ respectively and in no-remission group of proliferative lupus nephritis was $5169.20 \pm 394.76(\mathrm{pg} / \mathrm{ml})$ and $3220.18 \pm 499.85(\mathrm{pg} / \mathrm{ml})$ respectively. The difference of serum soluble IL-2R alpha level was significant between remission and non-remission group at baseline $p$ value 0.008 . In case of $24 \mathrm{hrs}$ UTP, the difference was not significant at base line but after 6 months of treatment the difference was significant in both group

\begin{tabular}{|l|c|c|c|}
\hline & Remission (n=13) & No-remission (n=5) & p-value \\
\hline IL-2R & & & $\mathbf{0 . 0 0 8}$ \\
\hline Baseline & $\mathbf{4 0 7 1 . 6 0 \pm 7 6 9 . 9 1}$ & $\mathbf{5 1 6 9 . 2 0 \pm 3 9 4 . 7 6}$ & $<0.001^{*}$ \\
\hline After 6 months & $925.98 \pm 363.10$ & $3220.18 \pm 499.85$ & \\
\hline p-value & $<0.001$ & 0.002 & \\
\hline UTP (g/24 hours) & & & $\mathbf{0 . 2 9 2}$ \\
\hline Baseline & $\mathbf{2 . 6 8} \pm \mathbf{1 . 0 1}$ & $\mathbf{3 . 2 5} \pm \mathbf{0 . 9 3}$ & $<0.001^{*}$ \\
\hline After 6 months & $0.69 \pm 0.48$ & $3.71 \pm 0.81$ & \\
\hline p-value & $<0.001$ & 0.420 & \\
\hline
\end{tabular}

Paired t test was done to see the level of significance; ${ }^{*}=$ Significance

Table 5: Correlation of IL-2R with UTP at baseline in proliferative lupus nephritis patients.

Correlation between IL-2R and UTP in remission group is a positive and no remission group there is negative correlation.

\begin{tabular}{|c|c|c|c|}
\hline \multicolumn{2}{|c|}{ Remission } & \multicolumn{2}{c|}{ No remission } \\
\hline $\mathrm{r}$ & $\mathrm{p}$-value & $\mathrm{r}$ & $\mathrm{p}$-value \\
\hline 0.251 & 0.408 & -0.774 & 0.124 \\
\hline
\end{tabular}

Table 6: Correlation between IL-2R and UTP in remission and no remission group of proliferative Lupus nephritis (class III \& class IV) (n=18)

According to Youden Index best cutoff value for IL-2R is $4595.4 \mathrm{mg} / \mathrm{ml}$ in prediction of remission in proliferative group. Sensitivity of this test to prediction of reemission was found to be $92.6 \%$ and specificity was found to be $84.6 \%$. 


\begin{tabular}{|c|c|c|c|}
\hline IL-2R & Sensitivity & Specificity & Youden Index \\
\hline 3853.1 & 1.000 & 0.308 & 0.308 \\
\hline 3928.3 & 1.000 & 0.385 & 0.385 \\
\hline 3991.8 & 1.000 & 0.462 & 0.462 \\
\hline 4034.2 & 1.000 & 0.538 & 0.538 \\
\hline 4057.8 & 1.000 & 0.615 & 0.615 \\
\hline 4191.1 & 1.000 & 0.692 & 0.692 \\
\hline 4395.1 & 1.000 & 0.769 & 0.769 \\
\hline 4595.4 & 0.926 & 0.846 & 0.772 \\
\hline 4768.7 & 0.800 & 0.846 & 0.646 \\
\hline 4982.3 & 0.600 & 0.846 & 0.446 \\
\hline 5187.3 & 0.600 & 0.923 & 0.523 \\
\hline 5334.3 & 0.400 & 0.923 & 0.323 \\
\hline
\end{tabular}

Table 7: Cutoff value for IL-2R in prediction of remission in proliferative group

\section{Discussion}

Systemic Lupus Erythematosus (SLE) is a chronic autoimmune disease which affects almost every system in the body with different degrees of severity [1]. Renal involvement in SLE is known as lupus nephritis, manifested by persistent proteinuria $\geq 0.5 \mathrm{gm} / 24$ hours or active sediment in urine [presence of glomerular hematuria $\geq 5 \mathrm{RBC} / \mathrm{hpf}$, with $\geq 2$ acanthocytes/hpf and/ or $\geq 1$ RBC cast, WBC cast (no infection), or both (Ref. ACR -2012).

Renal involvement in SLE significantly contributes to patient morbidity and mortality [9]. Hence, it is essential to find a noninvasive biomarker that could be used for early diagnosis of LN flares and for follow up [9].

Apart from current conventional biomarkers for lupus nephritis like urine sediments, proteinuria, anti-dsDNA antibodies and C3 or C4 are sometimes mislead for prediction of treatment response. Recently IL-2 R alpha has shown to be a good marker to predict treatment response of lupus nephritis. This study illustrated the potential utility of serum sIL-2R as biomarkers of LN.

Serum sIL-2R alpha is a good marker of lupus nephritis for follow-up as it falls in patients with good response and stays raised or rises when there is poor response. In this study, the clinical implications of serum IL-2R alpha as disease activity and assessment of treatment response tool have been assessed.

We found higher levels of serum sIL-2R in patients with proliferative nephritis compared to nonproliferative LN patients and with follow up, patients who achieved remission had signifIcant lower levels of serum sIL-2R than baseline levels with persistent or higher levels in patients without remission.

In this prospective observational study, a total of 27 patients with lupus nephritis were recruited. Most of the study subjects were females 24 (88.9\%). Maximum were in the age group of $21-30$ (44.4\%) years. It was similar to other study [12][13][14]. This can be explained by lupus nephritis is more common in female.

Renal biopsy was done in all patients. Among 27 lupus nephritis patients, the most common histopathological type was class IV (48.1\%) followed by class V (33.3\%) and class III (18.5\%). Near similar findings were observed in a study done [15] where the most common histopathological type was class IV (50\%), followed by class III (17.6\%) and class V (9\%) and where Proliferative glomerulonephritis (class III and IV) was detected in 31 (68.8\%) patients and class II and class V LN was detected in seven (15.5\%) patients each [7]. In both study number of class V lupus nephritis patient is less then class III probably due to two factors. Firstly, in both study all class of LN patients were include and secondly, combined class (III + V) and class (IV + V) lupus nephritis patient was more in both groups.

In our study serum sIL-2R alpha levels were high in proliferative (Class III+IV) lupus nephritis at baseline (4376.49 \pm $843.20 \mathrm{pg} / \mathrm{ml}$ ) then non proliferative lupus nephritis (Class - V) $(1801.98 \pm 205.82 \mathrm{pg} / \mathrm{ml})$. The concentration of serum 
sIL-2R alpha in proliferative lupus nephritis is higher than that in non-proliferative lupus nephritis. This agrees with studies conducted [7][10][16][17][18] and found the similar association too. Increased levels of IL-2R $\alpha$ in biological fluids correlate with increased $\mathrm{T} \& \mathrm{~B}$ cell activation.

In our study serum sIL-2R alpha level was found to be significantly higher in both proliferative and non-proliferative lupus nephritis patient at baseline and after 6 months of treatment mean serum sIL-2R alpha level was decreased significantly in both group $1563.26 \pm 1126.89(\mathrm{pg} / \mathrm{ml})$ respectively and $753.62 \pm 299.47(\mathrm{pg} / \mathrm{ml})$ respectively. Similar findings were observed in a study ${ }^{10}$ where 19 patients from lupus nephritis group were assess at presentation and 6 months after treatment. Serum soluble sIL-2R alpha levels were higher in patients with lupus nephritis before treatment and decreased significantly 6 months after treatment. Another study done [7] which recruited 45 patient and renal biopsy done all patients and similar result was observed.

Several published studies/data have evaluated IL-2R levels in relation to other serologic tests in lupus nephritis. Decreased levels of C3 and C4, elevated anti-ds DNA and increased proteinuria correlated with elevated sIL-2R levels. The present study confirmed these findings, in which elevated soluble IL-2R alpha levels were found to strongly correlate with increased proteinuria.

This finding correlated with study done by Davas [10]. From the above results it seems that the soluble receptors are as sensitive markers of disease activity as proteinuria.

This study revealed that the difference of baseline serum sIL-2R levels at base line between remission group (complete and partial) and no remission group of proliferative lupus nephritis was $4071.60 \pm 769.91(\mathrm{pg} / \mathrm{ml}) \& 5169.20 \pm 394.76$ $(\mathrm{pg} / \mathrm{ml})$ which was statically significant 'p value 0.008 ' but the difference of $24 \mathrm{hrs}$ UTP was $2.68 \pm 1.01 \& 3.25 \pm 0.93$ $\mathrm{gm} /$ day which was not statically significant $\mathrm{p}$ value was 0.292 . By measuring the baseline serum sIL-2R levels, we can predict the treatment response before starting the treatment in case of proliferative which was not possible by measuring the $24 \mathrm{hrs}$ UTP and the best cut-off value for IL-2R may be around $4595.4 \mathrm{mg} / \mathrm{ml}$ in prediction of remission in proliferative group with sensitivity $92.6 \%$ and specificity $84.6 \%$.

At the end of this study, it was shown that serum sIL-2R alpha level can detect proliferative and non-proliferative lupus nephritis and can predict treatment response with their base line value and their level significantly decrease after treatment in case of remission group which is comparable to the results in the study conducted by Davas [10] and Gupta [7].

The strengths of our study are that we are among the earliest to study the relation between serum sIL-2R and UTP with the histopathological renal class in renal biopsy. Another strength point is that we followed up our patients for 3 months and 6 months and studied the relation with the response to treatment. Limitations of our study may be the small sample size and the study was done in limited time span; subjects were collected from only one center; hence it may not represent the whole population of the country.

\section{Conclusion}

This study permits to conclude that serum soluble IL-2R alpha in patients with proliferative lupus nephritis (Class III \& Class IV), is significantly higher than those with non-proliferative lupus nephritis and correlates significantly with disease activity. After 6 months of treatment serum soluble IL-2R alpha level was significantly decreased in remission group in compression to non-remission group. In case of proliferative lupus nephritis (Class III \& Class IV) patient serum soluble IL-2R alpha level at baseline is significantly higher in non-remission group then remission group but $24 \mathrm{hrs}$ UTP is not significant. Hence, serum soluble IL-2R alpha might be a valuable monitoring tool to detect disease severity and to predict and monitor treatment response of lupus nephritis.

Limitation: It was a single center study with a relatively small sample size.

Funding: No funding sources

Conflict of interests: None declared

Ethical approval: Approved by ethical review committee, BSMMU, Dhaka, Bangladesh

Informed consent: taken from each patient enrolled. 


\section{References}

1. Gurevitz, S., Snyder, J., Wessel, E., Frey, J. and Williamson, B., 2013. Systemic lupus erythematosus: a review of the disease and treatment options. The ConsultantPharmacist, 28(2), pp.110-121.

2. Reyes-Thomas, J., Blanco, I. and Putterman, C., 2011. Urinary biomarkers in lupus nephritis. Clinical reviews in allergy \& immunology, 40(3), pp.138-150.

3. Bomback, A.S. and Appel, G.B., 2010. Updates on the treatment of lupus nephritis. Journal of the American Society of Nephrology, 21(12), pp.2028-2035.

4. Rovin, B.H. and Zhang, X., 2009. Biomarkers for lupus nephritis: the quest continues. Clinical Journal of the American Society of Nephrology, 4(11), pp.1858-1865.

5. Malvar, A., Pirruccio, P., Alberton, V., Lococo, B., Recalde, C., Fazini, B., N et al., 2015. Histologic versus clinical remission in proliferative lupus nephritis. Nephrology Dialysis Transplantation, 32(8), pp.1338-1344.

6. Bertsias, G.K., Tektonidou, M., Amoura, Z., Aringer, M., Bajema, I., Berden, J.H et al., 2012. Joint European League Against Rheumatism and European Renal Association-European Dialysis and Transplant Association (EULAR/ERAEDTA) recommendations for the management of adult and paediatric lupus nephritis. Annals of the rheumatic diseases, 71(11), pp.1771-1782.

7. Gupta, R., Yadav, A., Misra, R. and Aggarwal, A., 2015. Urinary sCD25 as a biomarker of lupus nephritis disease activity. Lupus, 24(3), pp.273-279.

8. Mok, C.C., 2010. Biomarkers for lupus nephritis: a critical appraisal. BioMed Research International, 2010.

9. Zeid, M.M.H., Baddour, N.M., El-Neily, D.A.E.M., Elshair, H.S. and Mamdouh, M., 2018. Study of urinary interferon gamma-induced protein 10 (IP-10) and urinary soluble CD 25 (sCD25) as markers of lupus nephritis and their relation to histological class. Alexandria journal of medicine, 54(4), pp.647-653.

10. Davas, E.M., Tsirogianni, A., Kappou, I., Karamitsos, D., Economidou, I. and Dantis, P.C., 1999. Serum IL-6, TNFa, p55 srTNFa, p75 srTNFa, srIL-2 $\alpha$ levels and disease acitivity in systemic lupus erythematosus. Clinical rheumatology, 18(1), pp.17-22.

11. Laut, J., Senitzer, D., Petrucci, R., Sablay, L.B., Barland, P. and Glicklich, D., 1992. Soluble interleukin-2 receptor levels in lupus nephritis. Clinical nephrology, 38(4), pp.179-184.

12. El-Shafey, E.M., Abdou, S.H. and Shareef, M.M., 2010. Is mycophenolate mofetil superior to pulse intravenous cyclophosphamide for induction therapy of proliferative lupus nephritis in Egyptian patients? Clinical and experimental nephrology, 14(3), pp.214-221.

13. Gunes, C., Keles, M., Uyanik, A., Cetinkaya, R. and Sari, R.A., 2010. Treatment Results of Patients with Lupus Nephritis: A Single Center's Experience. The Eurasian journal of medicine, 42(3), p.132.

14. Rabrenović, V., Poskurica, M., Kovačević, Z., Nešić, V., Savin, M., Mitić, B., et al., 2010. Treatment of lupus nephritis by mycophenolate mofetil. Kidney and Blood Pressure Research, 33(4), pp.297-303.

15. S.Sharma, M., Das, H.J., Doley, P.K. and Mahanta, P.J., 2019. Clinical and histopathological profile of lupus nephritis and response to treatment with cyclophosphamide: A single center study. Saudi Journal of Kidney Diseases and Transplantation,30(2), p.501.

16. EL Shaffy, E.M., EL Nagar, G.F., EL Bendary, A.S., Sabry, A.A. and Selim, A.G.A., 2008. Serum soluble interleukin-2 receptor alpha in systemic lupus erythematosus

17. Brugos, B., Vincze, Z., Sipka, S., Szegedi, G. and Zeher, M., 2012. Serum and urinary cytokine levels of SLE patients. Die Pharmazie-An International Journal of Pharmaceutical Sciences, 67(5), pp.411-413.

18. Guleria, A., Phatak, S., Dubey, D., Kumar, S., Zanwar, A., Chaurasia, S.et al., 2018. NMR-Based Serum Metabolomics Reveals Reprogramming of Lipid Dysregulation Following Cyclophosphamide-Based Induction Therapy in Lupus Nephritis. Journal of proteome research, 17(7), pp.2440-2448.

19. Petri, M.A., Martin, R.S., Scheinberg, M.A. and Furie, R.A., 2017. Assessments of fatigue and disease activity in patients with systemic lupus erythematosus enrolled in the Phase 2 clinical trial with blisibimod. Lupus, 26(1), pp.27-37.

20. Bombardier, C., 1992. and The Committee on Prognosis Studies in SLEDerivation of the SLEDAI. A disease activity index for lupus patients. Arthritis Rheum., 35, p.630.

21. Pitashny, M., Schwartz, N., Qing, X., Hojaili, B., Aranow, C., Mackay, M. and Putterman, C., 2007. Urinary lipocalin-2 is associated with renal disease activity in human lupus nephritis. Arthritis \& Rheumatism, 56(6), pp.1894-1903.

22. Mustafa, A.S., 2014. Urinary Monocyte Chemoattractant Protein-1 (mcp-1) Level Among Lupus Nephritis Patient and Its Correlation with Disease Activity Markers in Hospital Universiti Sains Malaysia, Kelantan (Doctoral dissertation, Universiti Sains Malaysia). 